\title{
Antibiofilm Efficacy of Positively Charged Imidazolium-Based Silver Nanoparticles in Enterococcus faecalis Using Quantitative Real-Time PCR
}

\author{
Mohammadreza Nabavizadeh,, ${ }^{1,2}$ Abbas Abbaszadegan, ${ }^{1,}$ Ahmad Gholami, ${ }^{3}$ Zahra Kadkhoda, ${ }^{4}$ Hosein \\ Mirhadi, ${ }_{1}^{1}$ Younes Ghasemi, ${ }^{3}$ Azam Safari, ${ }^{3}$ Bahram Hemmateenejad, ${ }^{5}$ Samira Dorostkar, ${ }^{5}$ and Hashem \\ Sharghi ${ }^{5}$ \\ ${ }^{1}$ Department of Endodontics, School of Dentistry, Shiraz University of Medical Sciences, Shiraz, IR Iran \\ ${ }^{2}$ Prevention of Oral and Dental Diseases Research Center, Dental School, Shiraz University of Medical Sciences, Shiraz, IR Iran \\ ${ }^{3}$ Pharmaceutical Sciences Research Center and Department of Pharmaceutical Biotechnology, School of Pharmacy, Shiraz University of Medical Sciences, Shiraz, IR Iran \\ ${ }^{4}$ Post graduate student, School of Dentistry, Shiraz University of Medical Sciences, Shiraz, IR Iran \\ ${ }^{5}$ Department of Chemistry, Shiraz University, Shiraz, IR Iran \\ "Corresponding author: Abbas Abbaszadegan, DDs, MSc, Ghasrodasht Avenue, Ghomabad Street, Shiraz Dental School, Postal code: 71956-15878, Shiraz, IR Iran. Tel: \\ +98-7136263192, Fax: +98-7136270325, E-mail: dr.abbaszadegan@gmail.com
}

Received 2016 November 23; Revised 2017 June 29; Accepted 2017 July 23.

\begin{abstract}
Background: Nanoparticles are made by different methodologies, which can affect the particle's features. Recently, imidazoliumcoated silver nanoparticles with a positive surface charge (PC Im-based AgNPs) have revealed favorable results as a root canal disinfectant. However, the antibacterial potency of these particles against biofilm form of Enterococcus faecalis, as the most resistant organism to eliminate in endodontic treatment, has not been investigated. It can be noted that removing this microorganism is associated with extremely effective disinfection.

Objectives: This study investigated the antibacterial efficacy of PC Im-based AgNPs at $5.7 \times 10^{-8} \mathrm{~mol} \mathrm{~L}^{-1}$ in comparison with $2.5 \%$ sodium hypochlorite $(\mathrm{NaOCl})$ and $2 \%$ chlorhexidine as the two broadly used endodontic irrigation solutions against biofilm E. faecalis using quantitative real-time polymerase chain reaction.

Methods: In total, 48 premolar teeth with a single root were infected with E. faecalis and then prepared with ProTaper rotary instruments. The samples were randomly allocated into 4 groups of 12 samples. Sterile saline, PC Im-based AgNPs, NaOCl, and chlorhexidine were used as irrigants. Sampling the root canals was implemented with paper points and Gates-Glidden drills. The reduction in E. faecalis counts was calculated and statistically analyzed by means of the Kruskal-Wallis and Mann-Whitney U tests.

Results: Irrigation with PC Im-based AgNPs or NaOCl was significantly more effective in bacterial count reduction compared to irrigation with chlorhexidine or sterile saline $(\mathrm{P}<0.05)$. There was no significant difference between PC Im-based AgNPs and NaOCl irrigants when either Gates-Glidden drills $(\mathrm{P}=0.751)$ or paper points $(\mathrm{P}=0.488)$ were employed. Chlorhexidine was significantly less efficient than PC Im-based AgNPs and $\mathrm{NaOCl}$ solutions $(\mathrm{P}<0.001)$; however, it was significantly better than sterile saline in both sampling approaches $(\mathrm{P}>0.001)$.

Conclusions: The PC Im-based AgNP solution revealed promising results as a root canal irrigant. This solution at $5.7 \times 10^{-8} \mathrm{~mol} \mathrm{~L}^{-1}$ was effectively able to eliminate biofilm $E$. faecalis and this was not significantly different from that of $2.5 \% \mathrm{NaOCl}$.

Keywords: Ionic Liquids, Real Time Polymerase Chain Reaction, Root Canal Therapy, Nanoparticles, Enterococcus faecalis
\end{abstract}

\section{Background}

Root canal infections are usually known as biofilmrelated infections induced by intracanal microorganisms (1). The success of endodontic treatment generally is determined by the competence of root canal disinfection. However, eliminating bacteria and their metabolites may not be thoroughly achieved because of the anatomical complexity of the root canal system, the buffering action of dentin, and the persistence of microorganisms (2, 3). En- terococcus faecalis is one of the most resistant organisms that survive after root canal treatments and play an important role in persistent periradicular lesions $(4,5)$. This bacterium is capable to persist in strict nutritional states within the root canal system, maintain $\mathrm{pH}$ homeostasis, attack the dentinal tubules, and attach to dentin and collagens in the biofilm form $(6,7)$. Hence, irrigants, which could remove this bacterium from the root canal space, are essential for successful disinfection.

Sodium hypochlorite $(\mathrm{NaOCl})$ and chlorhexidine are 
the most broadly used endodontic irrigation solutions with exemplary antibacterial effectiveness to root canal pathogens, including E. faecalis. Despite favourable qualities, $\mathrm{NaOCl}$ has disadvantages including the caustic effect, if inadvertently extruded to the periapical region, and the corrosive effect on metal objects $(8,9)$. The lack of ability to remove tissue remnants and little capability to kill gram-negative bacteria are the two major shortcomings of chlorhexidine, which makes it a complement rather than a major endodontic irrigant $(10,11)$. Therefore, studies are continually attempting to investigate and find efficient, non-toxic, and cost-effective disinfectants for root canal treatment.

In recent years, trends in application of silver nanoparticles (AgNPs) as antimicrobial mediators have developed in many fields, including endodontics, due to their high level of biocompatibility, particularly in low concentrations (12) and their broad spectrum of antibacterial efficacy (13-15). It has been speculated that AgNPs can attach to the cell wall of organisms and cause dysfunction in cellular permeability. Furthermore, they may enter the bacteria and affect their DNA and enzymes, eventually causing cell extermination $(16,17)$. The interaction between AgNPs and the target cells happens in an extremely short fraction of time because AgNPs have large surface area to volume ratio $(18,19)$. Therefore, AgNPs appear to prevent the development of resistance by the bacteria (17).

In a recent study evaluating the potential role of AgNPs in future endodontic practice, the positively charged imidazolium-based silver nanoparticles (PC Im-based AgNPs) have revealed promising results as a root canal disinfectant (20). Later on, it has been found that these NPs could affect the physicochemical properties of dentin and raised its surface roughness (21). Previous findings proved the outstanding antibacterial efficacy of these NPs against planktonic E. faecalis with or without dentin and their great cytocompatibility level. However, the antibacterial potency of these particles against biofilm E. faecalis has not been investigated.

\section{Objectives}

The aim of this study was to assess the antibacterial efficacy of these particles in root canals infected with E. faecalis relative to $2.5 \% \mathrm{NaOCl}$ and $2 \%$ chlorhexidine using quantitative real-time polymerase reaction (qPCR).

\section{Methods}

\subsection{Ethics Statement}

This study was approved by the ethics committee of Shiraz University of Medical Sciences (code: 5763).

\subsection{Irrigants}

The irrigants in this study were PC Im-based Ag NP solution (average size of $9 \mathrm{~nm}$ ) at $5.7 \times 10^{-8} \mathrm{~mol} \mathrm{~L}^{-1}$, which was synthesized based on the method defined by Abbaszadegan et al. (20), 2.5\% NaOCl (Sigma Aldrich Co., St. Louis, MO, USA), $2 \%$ chlorhexidine (FGM, Joinville, PR, Brazil), and 0.9 $\%$ sterile saline.

\subsection{Sample Collection and Preparation}

Forty-eight human premolar teeth with a single root and closed apices without any signs of fracture or caries were selected to be studied. These teeth were gathered from a group of teeth that had been extracted for orthodontic purposes. Each tooth was radiographed. Teeth with more than single canal or with complex anatomy or root length more or less than $12 \mathrm{~mm}$ were excluded. Any residual periodontal tissue or calculus was cleared from the root surfaces with an ultrasonic scaler. After disinfection of the teeth with $5.25 \% \mathrm{NaOCl}$ for $1 \mathrm{~h}$, they were kept in saline solution before use.

The access cavity was prepared. The working length was determined. To standardize the apical constriction diameter, each root canal was reamed and enlarged by means of a \#20 K-file (Mani Inc, Japan). The removal of smear layer was done using 5 mL 17\% EDTA (Dia-Prep Plus, Diadent Group International Inc., Chongju, Korea) for 3 miutesn and $5 \mathrm{~mL} \mathrm{2.5 \%} \mathrm{NaOCl}$ irrigation. Afterwards, to neutralize the remaining $\mathrm{NaOCl}, 5 \%$ sodium thiosulfate (Merck, Germany) was used for 1 minute.

The teeth were dipped in sterile brain heart infusion (BHI) (Himedia, India) broth and ultrasonicated for 1 minute. This was done in order to release any trapped air and to help penetration of the culture media into the irregularities of root canals. Afterwards, they were autoclaved for 20 minutes at $121^{\circ} \mathrm{C}$. Every 12 teeth were placed in a flask and then, each flask was immersed in BHI broth. Then, they were kept warm at $37^{\circ} \mathrm{C}$ for 24 hours and tested again to assess the efficiency of the sterilization procedures.

\subsection{Bacterial Biofilm Formation}

The pure strain of E. faecalis (PTCC1394) was used in this study. The samples were prepared for 24 hours at $37^{\circ} \mathrm{C}$ in BHI using a shaker incubator (G-25 Shaker Incubator, New Brunswick Scientific Co. Inc., New Brunswick, NJ, USA) at $150 \mathrm{rpm}$. Microbial growth was assessed based on turbidity changes over 24 hours. To prepare bacterial suspension $1 \mathrm{~mL}$ of a pure culture of E. faecalis was added to $5 \mathrm{~mL}$ of fresh BHI. Further, cell suspension was set spectrophotometrically at $1.5 \times 10^{8} \mathrm{CFU} \mathrm{mL}^{-1}$, which is equivalent to 0.5 McFarland standards. To inoculate each flask, $1 \mathrm{~mL}$ of this suspension was used. Enterococcus faecalis was grown up 
for 21 days where it was under a gentle shaking at the temperature of $37^{\circ} \mathrm{C}$.

Every other day, half of the culture media contaminated with the microorganism was replaced with fresh BHI under a laminar-flow hood to avoid medium saturation. Following the contamination period, four teeth were randomly observed using a scanning electron microscope (JSM-5800LV; JEOL, Tokyo, Japan) to confirm the colonization and biofilm formation of E. faecalis. The experimental teeth ( $\mathrm{n}=12$ in each group) were smoothly washed with phosphate-buffered saline to eliminate any remaining culture medium or floating bacteria. The apex of all teeth became impermeable with epoxy resin. Later, to expedite the handling and identification, the teeth were fixed vertically up to the cervical area using blocks made from silicon impression materials. Next, the outer surfaces of the crowns and the assemblies were decontaminated using $2.5 \% \mathrm{NaOCl}$. In total, in order to inactivate $\mathrm{NaOCl}, 5 \%$ sodium thiosulfate was used for 1 minute. Later, initial (S1) sampling was conducted by three paper cones (Orca, China), which were placed in the root canals for 1 minute.

\subsection{Irrigation Procedure}

The teeth were coded and randomly allocated into four groups based on the irrigants used as follows:

Group 1 $(n=12)$ : Sterile saline

Group $2(\mathrm{n}=12)$ : PC Im-based AgNPs

Group $3(\mathrm{n}=12): 2.5 \% \mathrm{NaOCl}$

Group $4(\mathrm{n}=12): 2 \% \mathrm{CHX}$

All the root canals were cleaned and shaped in a similar way by ProTaper rotary instruments (Dentsply, Switzerland) following the instruction conducted by the manufacturer up to file size F3. Irrigation of the root canals was done in each group by employing $2 \mathrm{~mL}$ of the designated solutions after changing each file (total of $10 \mathrm{~mL}$ ). This was done with the application of disposable syringes via 27gauge needles (NaviTip, Ultradent, South Jordan, UT) that was taken along to the canal long axis up to $1 \mathrm{~mm}$ short of the working length. The total time for the preparation of each sample was taken about 20 minutes. Before taking post-instrumentation(S2) samples, each canal was washed using the following solutions for 1 minute to inactivate the related irrigants: $0.07 \%$ lecithin and $0.5 \%$ Tween 80 for CHX, $0.4 \%$ sodium thioglycolate for AgNPs, and 5\% sodium thiosulfate for $\mathrm{NaOCl}$. Then, S2 samples were obtained sequentially using three \#30-paper cones placed to the working length for 1 minute.

Furthermore, dentin chips were collected by the sequential use of Gates-Glidden drills sizes no. 3, 4, and 5 (Mani, Tochigi, Japan). Averagely, each Gates-Glidden drill was employed for 10 seconds for three times up to $10 \mathrm{~mm}$ of the canal length. Then, the collected shavings were maintained at $-70^{\circ} \mathrm{C}$ in an incubator for 4 days until a fixed weight was obtained. Thereafter, they were confirmed to have similar weights using an electronic balance (AX200; Shimadzu Corp, Kyoto, Japan) and transferred to tryptic soy broth. The aliquots were analyzed by quantitative realtime PCR (Bio-Rad, Hercules, CA, USA) to obtain the threshold cycle (CT) value of the samples. Assessment of the samples was conducted with real-time PCR.

\subsection{DNA Extraction and Primer Design}

A bacterial genomic DNA isolation Kit (Promega, Madison, WI) was used to isolate the genomic DNA, based on the recommended protocol by the manufacturer, and it was scaled down to accommodate a 100 sample. UV-VIS spectrophotometry was employed to determine the purity and concentration of DNA. Pure E. faecalis-obtained DNA was diluted in sterile Tris-EDTA buffer at $\mathrm{pH} 8$ and stored at $-20^{\circ} \mathrm{C}$ before the commencement of the experiment (22). The primers were designed and the specificity of the primer sequences was identified similar to the method suggested by Malorny et al. (23).

\subsection{Efficiency of the Reaction and Determination of the Linear- ity}

Negative controls were set in duplicate along with the experimental total DNA samples in order to normalize any probable background signals following amplification. To determine E. faecalis counts, total DNA standards from an $E$. faecalis laboratory strain were prepared in 10-fold dilutions from $10 \mathrm{ng} \mathrm{mL}^{-1}$ to $100 \mathrm{fg} \mathrm{mL}^{-1}$. Real time PCR was implemented. Based on data analysis, the standard curves were obtained from a series of dilution in concentration range of $2 \times 10^{6}$ to $2 \mathrm{CFU} / \mathrm{mL}$ organisms. Then, standard curves were created for the extracted, quantified, and amplified DNA. The efficiency of the amplification and the correlation coefficient $\left(\mathrm{R}^{2}\right)$ were determined (22-24).

\subsection{Statistical Analysis}

The normality of data was evaluated by KolmogorovSmirnov test. The Wilcoxon signed rank test was employed to evaluate the reduction in E. faecalis counts from S1 to S2 samples. Intergroup analysis was performed using Kruskal-Wallis and Mann-Whitney U tests. The correlation between the two sampling methods (using paper point vs. Gate-Glidden drills) was determined by Spearman's correlation coefficient test. SPSS 15.0 software package (SPSS, Chicago, IL, USA) was employed for all statistical analyses. A P value below 0.05 was considered significant. 


\section{Results}

Scanning electron microscopic analysis of the four control teeth revealed successful colonization of E. faecalis in the root canal walls. This was also reconfirmed by the results of qPCR in S1 samples of all experimental teeth. Intragroup analyses demonstrated a highly significant bacterial reduction from $\mathrm{S} 1$ to $\mathrm{S} 2$ for both sampling methods in all the experimental groups $(\mathrm{P}<0.001)$. Table 1 demonstrates the mean and median of the number of CFUs obtained for all groups. Intergroup analysis of S1 samples revealed no significant differences $(P=0.147)$ between the groups, indicating an identical reference for bacterial load induced by the employed method of contamination.

Irrigation with AgNPs or $\mathrm{NaOCl}$ was significantly more effective in bacterial count reduction compared to irrigation with chlorhexidine or sterile saline $(\mathrm{P}<0.05)$. No significant differences were observed between AgNP and $\mathrm{NaOCl}$ irrigants when either Gates-Glidden drills $(\mathrm{P}=0.751)$ or paper points $(\mathrm{P}=0.488)$ were employed through different sampling approaches. Chlorhexidine was significantly less efficient than AgNPs and $\mathrm{NaOCl}$ solutions $(\mathrm{P}<0.001)$; however, it was significantly better than sterile saline in both sampling approaches $(\mathrm{P}>0.001)$.

\section{Discussion}

Mature biofilm formation requires a multiparty process. It starts with a linkage of an organism to a surface and continues with cellular interaction and colony formation (25). Likewise, bacterial biofilms in root canal are a population of cells, enclosed in a hydrated matrix of exopolymeric substances, nucleic acids, proteins, polysaccharides that are attached irreversibly to dentin surfaces (26). In comparison with the planktonic form, bacteria in a biofilm structure behave in a different mode because the physiological characteristics of biofilms provide a safety shelter for them against antibacterial irrigation solutions $(27,28)$.

Enterococci, known as opportunistic microorganisms, are normal residents of the oral cavity. Enterococcus faecalis as the most well-known enterococci species is in charge of almost all persistent periradicular lesions $(4,5)$. Recent studies have reported the excellent antibacterial activity of different synthesized AgNPs against planktonic E. faecalis (29-31). However, these studies were limited by the lack of investigation on antimicrobial properties of these nanoparticles against the biofilm E. faecalis. The current in vitro study was directed to shed light on the antimicrobial effectiveness of PC Im-based AgNPs when employed as a clinical irrigant against E. faecalis and compare it with the current clinical standards $2.5 \% \mathrm{NaOCl}$ and $2 \% \mathrm{CHX}$.
We found that the nanosilver solution at $5.7 \times 10^{-8} \mathrm{~mol}$ $\mathrm{L}^{-1}$ was equally potent as $2.5 \% \mathrm{NaOCl}$ against the biofilm form of E. faecalis. Electrostatic interaction plays a major role in antibacterial activity of AgNP, bearing in mind the negative charge of the bacteria due to their surface proteins (32). These proteins are necessary for membrane transport, cell wall synthesis, and other vital cellular roles (33). The synthesized AgNPs in this study were $9 \mathrm{~nm}$ in size. The particles with small sizes can provide a greater surface area and are able easily to reach the bacterial nuclear content (34). Moreover, previous studies have reported that small nanoparticles with the size ranging from 1 to 10 $\mathrm{nm}$ had the highest antibacterial effectiveness due to their ability to bind to the cell membrane and weakening its respiration and permeability $(14,35)$.

The results of the present investigation indicated that all experimental irrigants, including sterile saline, could promote a significant reduction in intracanal bacterial counts. This was in line with several previous studies showing the efficacy of the flushing action (36-38). Studies comparing the antibacterial effectiveness of $\mathrm{NaOCl}$ and chlorhexidine against E. faecalis revealed inconsistent results. While some studies found that $\mathrm{NaOCl}$ has lower effectiveness against E. faecalis (39-41), others indicated that chlorhexidine is less effective $(42,43)$ and many studies show little or no difference between their antibacterial efficacy $(38,44,45)$. The results of our study indicated that $\mathrm{NaOCl}$ was significantly more effective than chlorhexidine in reducing $E$. faecalis biofilm. The discrepancy between the results of studies might be attributed to the different methodology used.

We also revealed that AgNPs and $\mathrm{NaOCl}$ were significantly more effective than chlorhexidine or normal saline; however, no significant difference was detected between AgNPs and NaOCl. On the contrary, Wu et al. (46) showed that AgNPs were unable to eliminate the residual biofilm of E. faecalis formed on dentinal blocks when used as an irrigant rather than a medicament. In their study, a shorttime irrigation of 2 min was employed while in the present study a 20-min irrigation protocol was used in a simulated clinical condition. Importantly, when the resistance of biofilm polymeric matrix is considered, longer contact times may provide variation in the observed results, leading to different conclusions. Inconsistent with the findings of Wu et al. study (46), Mozayeni and co-workers (47) concluded that AgNP gel was ineffective against E. faecalis when compared to calcium hydroxide, $2 \%$ chlorhexidine gel, and triple antibiotic paste as intracanal medicaments. This discrepancy may be due to different applied concentrations of AgNPs, different synthesis procedures, their relevant physical properties, and the possible effect of carriers on inhibiting the release of AgNPs from different for- 
Table 1. CFU Counts in Pre- and Post-Instrumentation Samples ${ }^{\mathrm{a}, \mathrm{b}}$

\begin{tabular}{l|c|c|c}
\hline Group & S1 & S2 (Paper Point) & S2 (Gates-Glidden Drills) \\
\hline Sterile saline & $3.60 \times 10^{9}\left(4.24 \times 10^{9} \pm 2.86 \times 10^{9}\right) \mathrm{Aa}$ & $1.08 \times 10^{9}\left(1.76 \times 10^{9} \pm 1.94 \times 10^{9}\right) \mathrm{Ab}$ & $0.16 \times 109\left(0.41 \times 10^{9} \pm 0.62 \times 10^{9}\right) \mathrm{Ab}$ \\
\hline PC Im-based AgNPs & $2.42 \times 10^{9}\left(4.98 \times 10^{9} \pm 8.01 \times 10^{9}\right) \mathrm{Aa}$ & $1.41 \times 10^{2}\left(2.26 \times 10^{2} \pm 1.92 \times 10^{2}\right) \mathrm{Bb}$ & $8.15 \times 10^{1}\left(9.65 \times 10^{1} \pm 7.66 \times 10^{1}\right) \mathrm{Bb}$ \\
\hline NaOCl & $2.22 \times 10^{9}\left(6.94 \times 10^{9} \pm 10.37 \times 109\right) \mathrm{Aa}$ & $1.50 \times 10^{2}\left(2.11 \times 10^{2} \pm 1.86 \times 10^{2}\right) \mathrm{Bb}$ & $7.15 \times 10^{1}\left(8.83 \times 10^{1} \pm 8.17 \times 10^{1}\right) \mathrm{Bb}$ \\
\hline CHX & $1.35 \times 10^{9}\left(3.03 \times 10^{9} \pm 4.42 \times 10^{9}\right) \mathrm{Aa}$ & $4.28 \times 10^{2}\left(9.20 \times 10^{2} \pm 1.24 \times 10^{3}\right) \mathrm{Cb}$ & $9.32 \times 10^{2}\left(1.57 \times 10^{3} \pm 1.87 \times 10^{3}\right) \mathrm{Cb}$ \\
\hline
\end{tabular}

${ }^{a}$ Read vertically, uppercase letters denote between-group comparisons regarding the number of CFUs in S1 or S2 samples. Read horizontally, lowercase letters denote pre-instrumentation and post-instrumentation CFU comparisons in each group. Equal letters denotes lack of statistically significant difference.

${ }^{b}$ Data here are as Median (mean $\left.\pm S D\right)$.

mulation of medicaments.

Furthermore, in this study, extracted human teeth, which might better simulate the clinical setting as compared to dentinal blocks or culture medium, were used. Accordingly, it was possible to accompany the instrumentation procedures with irrigation protocols that mimic clinical situations. In this study, the apical diameter of each root canal was first standardized to K-file \#20. After that, root canals were sterilized, inoculated, and prepared and the efficacy of the test irrigants was examined. This methodology was similar to the method of a previous study by Tran et al. (48) and it was adopted because it was closer to clinical condition. Microbiological sampling by Gates-Glidden drills up to size \# 5 was selected to harvest dentinal debris up to 400-micron depth because of the known propensity of E. faecalis to proliferate in the deeper layers of dentinal tubes. In addition, sterile paper points were employed to engage the organisms floating in the root canal space.

In this study, the bacterial colony counts of microorganisms inside the dentinal tubules were evaluated by qPCR. PCR is a sensitive method for quick detection of microbial species that are difficult or impossible to culture (49). Real time PCR enables us to detect individual target species along with the quantification of bacteria in clinical samples. The other advantage of this technique is its limited contamination due to the avoidance of post amplification manipulation. One limitation of this study was that teeth with a single root and simple anatomic structures were used, which may differ from the clinical conditions. In addition, bacterial species were cultured under optimal in vitro conditions, which included nutrients that are rarely found in clinical settings. Therefore, data extrapolation to clinical situations should be made with caution because of inherent limitation of in vitro studies. Further investigations are suggested to determine the tooth staining, allergic potential, and long-term safety of this new irrigant.

\subsection{Conclusions}

The PC Im-based AgNP solution revealed promising results proposed for future endodontic treatments. This irrigant at $5.7 \times 10^{-8} \mathrm{~mol} \mathrm{~L}^{-1}$ was effectively able to eliminate biofilm E. faecalis and this was not significantly different from the effectiveness of $2.5 \% \mathrm{NaOCl}$.

\section{Acknowledgments}

The authors thank the vice-chancellery of Shiraz University of Medical Sciences for supporting this research (grant \# 5763). This manuscript is based on a postgraduate thesis by Dr. Zahra Kadkhoda. The authors would also like to thank Dr. Mehrdad Vosooghi and Dr. Shahram Hamedani, of the research development center, for their valuable comments to improve the quality of this work.

\section{References}

1. George S, Kishen A. Effect of tissue fluids on hydrophobicity and adherence of Enterococcus faecalis to dentin. J Endod. 2007;33(12):14215. doi: 10.1016/j.joen.2007.07.035. [PubMed: 18037050].

2. Ferraz CC, Gomes BP, Zaia AA, Teixeira FB, Souza-Filho FJ. In vitro assessment of the antimicrobial action and the mechanical ability of chlorhexidine gel as an endodontic irrigant. J Endod. 2001;27(7):4525. [PubMed: 11503994].

3. Portenier I, Haapasalo H, Rye A, Waltimo T, Orstavik D, Haapasalo M. Inactivation of root canal medicaments by dentine, hydroxylapatite and bovine serum albumin. Int Endod J. 2001;34(3):184-8. [PubMed: 12193263].

4. Molander A, Reit C, Dahlen G, Kvist T. Microbiological status of root-filled teeth with apical periodontitis. Int Endod J. 1998;31(1):1-7. [PubMed: 9823122].

5. Pinheiro ET, Gomes BP, Ferraz CC, Sousa EL, Teixeira FB, Souza-Filho FJ. Microorganisms from canals of root-filled teeth with periapical lesions. Int Endod J. 2003;36(1):1-11. [PubMed: 12656508].

6. Siqueira JJ, Lopes HP. Mechanisms of antimicrobial activity of calcium hydroxide: a critical review. Int Endod J. 1999;32(5):361-9. [PubMed: 10551109].

7. George S, Kishen A, Song KP. The role of environmental changes on monospecies biofilm formation on root canal wall by Enterococcus faecalis. JEndod. 2005;31(12):867-72. [PubMed: 16306820]. 
8. O'Hoy PY, Messer HH, Palamara JE. The effect of cleaning procedures on fracture properties and corrosion of NiTi files. Int Endod J. 2003;36(11):724-32. [PubMed: 14641435].

9. Cheung GS, Stock CJ. In vitro cleaning ability of root canal irrigants with and without endosonics. Int EndodJ. 1993;26(6):334-43. [PubMed: 8144242].

10. Naenni N, Thoma K, Zehnder M. Soft tissue dissolution capacity of currently used and potential endodontic irrigants. J Endod. 2004;30(11):785-7. [PubMed: 15505511].

11. Emilson CG. Susceptibility of various microorganisms to chlorhexidine. Scand J Dent Res. 1977;85(4):255-65. [PubMed: 266752].

12. Gomes-Filho JE, Silva FO, Watanabe S, Cintra LT, Tendoro KV, Dalto LG, et al. Tissue reaction to silver nanoparticles dispersion as an alternative irrigating solution. J Endod. 2010;36(10):1698-702. doi: 10.1016/j.joen.2010.07.007. [PubMed: 20850681].

13. Guzman M, Dille J, Godet S. Synthesis and antibacterial activity of silver nanoparticles against gram-positive and gram-negative bacteria. Nanomedicine. 2012;8(1):37-45. doi: 10.1016/j.nano.2011.05.007. [PubMed: 21703988].

14. Morones JR, Elechiguerra JL, Camacho A, Holt K, Kouri JB, Ramirez JT, et al. The bactericidal effect of silver nanoparticles. Nanotechnology. 2005;16(10):2346-53. doi: 10.1088/0957-4484/16/10/059. [PubMed: 20818017].

15. Abbaszadegan A, Ghahramani Y, Gholami A HB, Dorostkar S, Nabavizadeh $M$. The effect of charge at the surface of silver nanoparticles on antimicrobial activity against gram-positive and gramnegative bacteria: a preliminary study. Journal of Nanomaterials. ;2015(2015):720654. doi:10.1155/2015/720654.

16. Xiu ZM, Zhang QB, Puppala HL, Colvin VL, Alvarez PJ. Negligible particle-specific antibacterial activity of silver nanoparticles. Nano Lett. 2012;12(8):4271-5. doi: 10.1021/nl301934w. [PubMed: 22765771].

17. Rai MK, Deshmukh SD, Ingle AP, Gade AK. Silver nanoparticles: the powerful nanoweapon against multidrug-resistant bacteria. $J$ Appl Microbiol. 2012;112(5):841-52. doi: 10.1111/j.1365-2672.2012.05253.x. [PubMed: 22324439].

18. Cheng Z, Al Zaki A, Hui JZ, Muzykantov VR, Tsourkas A. Multifunctional nanoparticles: cost versus benefit of adding targeting and imaging capabilities. Science. 2012;338(6109):903-10. doi: 10.1126/science.1226338. [PubMed: 23161990].

19. Moghadas L, Narimani T, Shahmoradi M. Antimicrobial activity of a new nanobased endodontic irrigation solution: In vitro study. Dent Hypotheses. 2012;3(4):142. doi:10.4103/2155-8213.106838.

20. Abbaszadegan A, Nabavizadeh M, Gholami A, Aleyasin ZS, Dorostkar $S$, Saliminasab M, et al. Positively charged imidazolium-based ionic liquid-protected silver nanoparticles: a promising disinfectant in root canal treatment. Int Endod J. 2015;48(8):790-800. doi: 10.1111/iej.12377. [PubMed: 25269666].

21. Farshad M, Abbaszadegan A, Ghahramani Y, Jamshidzadeh A. Effect of Imidazolium-Based Silver Nanoparticles on Root Dentin Roughness in Comparison with Three Common Root Canal Irrigants. Iran Endod J. 2017;12(1):83-6. doi: 10.22037/iej.2017.17. [PubMed: 28179931].

22. Kumar R, Surendran PK, Thampuran N. Rapid quantification of Salmonella in seafood by real-time PCR assay. J Microbiol Biotechnol. 2010;20(3):569-73. [PubMed: 20372029].

23. Malorny B, Bunge C, Helmuth R. A real-time PCR for the detection of Salmonella Enteritidis in poultry meat and consumption eggs. J Microbiol Methods. 2007;70(2):245-51. doi: 10.1016/j.mimet.2007.04.013. [PubMed: 17512995].

24. Nam HM, Srinivasan V, Gillespie BE, Murinda SE, Oliver SP. Application of SYBR green real-time PCR assay for specific detection of Salmonella spp. in dairy farm environmental samples. Int J Food Microbiol. 2005;102(2):161-71. doi: 10.1016/j.ijfoodmicro.2004.12.020. [PubMed: 15913820].

25. O'Toole G, Kaplan HB, Kolter R. Biofilm formation as microbial development. Annu Rev Microbiol. 2000;54:49-79. doi: 10.1146/annurev.micro.54.1.49. [PubMed: 11018124]
26. Costerton JW. Cystic fibrosis pathogenesis and the role of biofilms in persistent infection. Trends Microbiol. 2001;9(2):50-2. [PubMed 11173226].

27. Stuart $\mathrm{CH}$, Schwartz SA, Beeson TJ, Owatz CB. Enterococcus faecalis: its role in root canal treatment failure and current concepts in retreatment. J Endod. 2006;32(2):93-8. doi: 10.1016/j.joen.2005.10.049. [PubMed: 16427453].

28. Wang Z, Shen Y, Ma J, Haapasalo M. The effect of detergents on the antibacterial activity of disinfecting solutions in dentin. J Endod. 2012;38(7):948-53. doi: 10.1016/j.joen.2012.03.007. [PubMed 22703659].

29. Bruniera JF, Silva-Sousa YT, Lara MG, Pitondo-Silva A, Marcaccini AM Miranda CE. Development of intracanal formulation containing silver nanoparticles. Braz Dent J. 2014;25(4):302-6. [PubMed: 25250493].

30. Krishnan R, Arumugam V, Vasaviah SK. The MIC and MBC of Silver Nanoparticles against Enterococcus faecalis - A Facultative Anaerobe. J Nanomed Nanotechnol. 2015;6(3):285. doi: 10.4172/2157-7439.1000285.

31. Lotfi M, Vosoughhosseini S, Ranjkesh B, Khani S, Saghiri M, Zand V. Antimicrobial efficacy of nanosilver, sodium hypochlorite and chlorhexidine gluconate against Enterococcus faecalis. Afr J Biotechnol. 2011;10(35):6799-803. doi: 10.5897/AJB11.240.

32. El Badawy AM, Silva RG, Morris B, Scheckel KG, Suidan MT, Tolaymat TM. Surface charge-dependent toxicity of silver nanoparticles. Environ Sci Technol. 2011;45(1):283-7. doi:10.1021/es1034188. [PubMed: 21133412]

33. Javidi M, Afkhami F, Zarei M, Ghazvini K, Rajabi O. Efficacy of a combined nanoparticulate/calcium hydroxide root canal medication on elimination of Enterococcus faecalis. Aust Endod J. 2014;40(2):61-5. doi: 10.1111/aej.12028. [PubMed: 25244219].

34. Thiel J, Pakstis L, Buzby S, Raffi M, Ni C, Pochan DJ, et al. Antibacterial properties of silver-doped titania. Small. 2007;3(5):799-803. doi: 10.1002/smll.200600481. [PubMed: 17340662].

35. Martinez-Castanon GA, Nino-Martinez N, Martinez-Gutierrez F, Martinez-Mendoza JR, Ruiz F. Synthesis and antibacterial activity of silver nanoparticles with different sizes. J Nanoparticle Res. 2008;10(8):1343-8. doi: 10.1007/s11051-008-9428-6.

36. Brito PR, Souza LC, Machado de Oliveira IC, Alves FR, De-Deus $\mathrm{G}$, Lopes HP, et al. Comparison of the effectiveness of three irrigation techniques in reducing intracanal Enterococcus faecalis populations: an in vitro study. J Endod. 2009;35(10):1422-7. doi: 10.1016/j.joen.2009.07.001. [PubMed: 19801244].

37. Siqueira JJ, Rocas IN, Favieri A, Lima KC. Chemomechanical reduction of the bacterial population in the root canal after instrumentation and irrigation with $1 \%, 2.5 \%$, and $5.25 \%$ sodium hypochlorite. $J$ Endod. 2000;26(6):331-4. doi: 10.1097/00004770-200006000-00006. [PubMed: 11199749].

38. Siqueira JJ, Rocas IN, Paiva SS, Guimaraes-Pinto T, Magalhaes KM, Lima KC. Bacteriologic investigation of the effects of sodium hypochlorite and chlorhexidine during the endodontic treatment of teeth with apical periodontitis. Oral Surg Oral Med Oral Pathol Oral Radiol Endod. 2007;104(1):122-30. doi: 10.1016/j.tripleo.2007.01.027. [PubMed: 17499528].

39. Dametto FR, Ferraz CC, Gomes BP, Zaia AA, Teixeira FB, de Souza-Filho FJ. In vitro assessment of the immediate and prolonged antimicrobial action of chlorhexidine gel as an endodontic irrigant against Enterococcus faecalis. Oral Surg Oral Med Oral Pathol Oral Radiol Endod. 2005;99(6):768-72. doi: 10.1016/j.tripleo.2004.08.026. [PubMed: 15897866].

40. Menezes MM, Valera MC, Jorge AO, Koga-Ito CY, Camargo CH, Mancini MN. In vitro evaluation of the effectiveness of irrigants and intracanal medicaments on microorganisms within root canals. Int Endod J. 2004;37(5):311-9. doi: 10.1111/j.0143-2885.2004.00799.x. [PubMed: 15086752].

41. Siqueira JJ, Rocas IN, Santos SR, Lima KC, Magalhaes FA, de Uzeda $M$. Efficacy of instrumentation techniques and irrigation regimens in reducing the bacterial population within root canals. $J$ En- 
dod. 2002;28(3):181-4. doi: 10.1097/00004770-200203000-00009. [PubMed: 12017176].

42. Ringel AM, Patterson SS, Newton CW, Miller $\mathrm{CH}$, Mulhern JM. In vivo evaluation of chlorhexidine gluconate solution and sodium hypochlorite solution as root canal irrigants. J Endod. 1982;8(5):2004. doi: 10.1016/S0099-2399(82)80354-3. [PubMed: 6955420].

43. Vianna ME, Horz HP, Gomes BP, Conrads G. In vivo evaluation of microbial reduction after chemo-mechanical preparation of human root canals containing necrotic pulp tissue. Int Endod J. 2006;39(6):484-92. doi: 10.1111/j.1365-2591.2006.01121.x. [PubMed: 16674744].

44. Ercan E, Ozekinci T, Atakul F, Gul K. Antibacterial activity of $2 \%$ chlorhexidine gluconate and $5.25 \%$ sodium hypochlorite in infected root canal: in vivo study. $J$ Endod. 2004;30(2):84-7. doi: 10.1097/00004770-200402000-00005. [PubMed: 14977302].

45. Rocas IN, Siqueira JJ. Comparison of the in vivo antimicrobial effectiveness of sodium hypochlorite and chlorhexidine used as root canal irrigants: a molecular microbiology study.J Endod. 2011;37(2):143-50. doi: 10.1016/j.joen.2010.11.006. [PubMed: 21238793].

46. Wu D, Fan W, Kishen A, Gutmann JL, Fan B. Evaluation of the antibacterial efficacy of silver nanoparticles against Enterococcus faecalis biofilm. J Endod. 2014;40(2):285-90. doi: 10.1016/j.joen.2013.08.022. [PubMed: 24461420].

47. Mozayeni MA, Haeri A, Dianat O, Jafari AR. Antimicrobial effects of four intracanal medicaments on enterococcus faecalis: an in vitro study. Iran Endod J. 2014;9(3):195-8. [PubMed: 25031593].

48. Tran KT, Torabinejad M, Shabahang S, Retamozo B, Aprecio RM, Chen JW. Comparison of efficacy of pulverization and sterile paper point techniques for sampling root canals. J Endod. 2013;39(8):1057-9. doi: 10.1016/j.joen.2013.04.012. [PubMed: 23880277].

49. Siqueira JJ, Rocas IN. PCR methodology as a valuable tool for identification of endodontic pathogens. J Dent. 2003;31(5):333-9. [PubMed: 12799118]. 